\title{
Retinal Pigment Epithelium Cell Alignment on Nanostructured Collagen Matrices
}

\author{
Stefan Ulbrich ${ }^{a}$ Jens Friedrichs ${ }^{b, f}$ Monika Valtink $^{a}$ Simo Murovski ${ }^{a}{ }^{d}$ \\ Clemens M. Franz ${ }^{b, e}$ Daniel J. Müller ${ }^{b, c, f}$ Richard H.W. Funk ${ }^{a, c}$ \\ Katrin Engelmann ${ }^{c, d}$ \\ a Institute of Anatomy, ${ }^{b}$ Cellular Machines Group, and ${ }^{\mathrm{C} C R T D / D F G ~ C e n t e r ~ f o r ~ R e g e n e r a t i v e ~ T h e r a p i e s ~}$ \\ Dresden - Cluster of Excellence, Biotechnology Center, TU Dresden, Dresden, ${ }^{\mathrm{d}}$ Department of Ophthalmology,

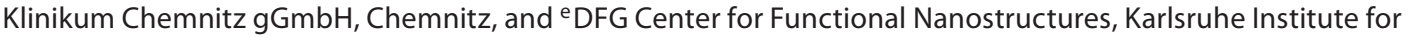 \\ Technology (KIT), Karlsruhe, Germany; ${ }^{f}$ Department of Biosystems, Science and Engineering (BSSE), ETH Zürich, \\ Basel, Switzerland
}

\section{Key Words}

Retinal pigment epithelium $\cdot$ Nanopatterned collagen matrix $\cdot$ Collagen cross-linking $\cdot$ Alignment $\cdot \alpha_{2}$ integrin

\begin{abstract}
We investigated attachment and migration of human retinal pigment epithelial cells (primary, SV40-transfected and ARPE-19) on nanoscopically defined, two-dimensional matrices composed of parallel-aligned collagen type I fibrils. These matrices were used non-cross-linked (native) or after riboflavin/UV-A cross-linking to study cell attachment and migration by time-lapse video microscopy. Expression of collagen type I and IV, MMP-2 and of the collagen-binding integrin subunit $\alpha_{2}$ were examined by immunofluorescence and Western blotting. SV40-RPE cells quickly attached to the nanostructured collagen matrices and aligned along the collagen fibrils. However, they disrupted both native and cross-
\end{abstract}

All experiments were conducted at the Institute of Anatomy and the Biotechnology Center, TU Dresden.

\section{KARGER \\ Fax +4161306 1234 \\ E-Mail karger@karger.ch}

www.karger.com (c) 2011 S. Karger AG, Basel

$1422-6405 / 11 / 1946-0443 \$ 38.00 / 0$

Accessible online at:

www.karger.com/cto linked collagen matrices within $5 \mathrm{~h}$. Primary RPE cells aligned more slowly without destroying either native or cross-linked substrates. Compared to primary RPE cells, ARPE-19 cells showed reduced alignment but partially disrupted the matrices within $20 \mathrm{~h}$ after seeding. Expression of the collagen type I-binding integrin subunit $\alpha_{2}$ was highest in SV40-RPE cells, lower in primary RPE cells and almost undetectable in ARPE-19 cells. Thus, integrin $\alpha_{2}$ expression levels directly correlated with the degree of cell alignment in all examined RPE cell types. Specific integrin subunit $\alpha_{2}$-mediated matrix binding was verified by preincubation with an $\alpha_{2}$-function-

\section{Abbreviations used in this paper}

$\begin{array}{ll}\text { AMD } & \text { age-related macular degeneration } \\ \text { ECM } & \text { extracellular matrix } \\ \text { MMP } & \text { matrix metalloproteinase } \\ \text { RPE } & \text { retinal pigment epithelium } \\ \text { SV40 } & \text { Simian virus } 40 \\ \text { UV-A } & \text { ultraviolet-A }\end{array}$


blocking antibody, which impaired cell adhesion and alignment to varying degrees in primary and SV40-RPE cells. Since native matrices supported extended and directed primary RPE cell growth, optimizing the matrix production procedure may in the future yield nanostructured collagen matrices serving as transferable cell sheet carriers.

Copyright $\odot 2011$ S. Karger AG, Basel

\section{Introduction}

Age-related macular degeneration (AMD), a major cause of irreversible central vision loss in industrialized countries, is one of several diseases attributed to the loss of retinal pigment epithelium (RPE) integrity [Zarbin, 2003]. It has been suggested that vision can be restored in AMD patients by establishing a healthy choriocapillaris-RPE-photoreceptor interface [Del Priore et al., 2002]. To this end, different methods to replace damaged RPE cells have been explored. Transplantation of RPE sheets was found to be more suitable than injection of RPE cell suspensions, as assembled cells may already carry spatial information [Kubota et al., 2006]. Recent studies have revealed that although uncultured aged adult RPE cells are not suitable for resurfacing Bruch's membrane [Tsukahara et al., 2002], resurfacing is possible with cultured fetal and adult RPE cells [Castellarin et al., 1998; Zarbin, 2003]. Moreover, in vitro cultivation induces upregulation of $\alpha_{1-5}$ integrin subunit production in RPE cells, which facilitates successful cell attachment and spreading on Bruch's membrane [Imai et al., 2007; Gullapalli et al., 2008]. Hence, characterization of the interaction of RPE cell populations with their microenvironment is required to establish appropriate cell culture models for developing cell or tissue transplantation strategies involving transferable sheets of cultured RPE monolayers.

The fragile nature of RPE monolayers requires the use of supportive materials as carriers for cell sheet engineering. Collagen matrices could potentially serve as such a supportive scaffold [Thumann et al., 2006; Cisneros et al., 2007]. In vivo, RPE cell adhesion is only mediated to a small extent by binding to collagen type I [Marshall et al., 1998; Del Priore et al., 2002]. However in AMD, the inner layers of Bruch's membrane, which consist mainly of collagen type I and III, are exposed to RPE cells [Del Priore et al., 2002]. It was shown that RPE cells grown on ultrathin $(2-7 \mu \mathrm{m})$ three-dimensional collagen type I matrices exhibit an epithelial morphology and form functional monolayers that were suitable for subretinal transplan- tation [Lu et al., 2007; Thumann et al., 2009]. However, the specific interaction of cells with the ultrastructure of the collagen matrix was not examined.

Recently, a method to create structurally well-defined and nanoscopically reproducible two-dimensional collagen type I matrices was developed. These matrices are composed of parallel fibrils that form a two-dimensional planar layer with a thickness of approximately $3 \mathrm{~nm}$ [Cisneros et al., 2007]. Depending on the preparation conditions, the native D-periodicity of $67 \mathrm{~nm}$ could be preserved in these matrices. With regard to the use of collagen type I matrices as carriers for transplantable RPE cell sheets it is of utmost interest to know if RPE cells attach specifically or unspecifically to collagen type I. Due to their defined nanostructure, two-dimensional collagen type I matrices are an ideal tool to study the interaction of RPE with collagen type I.

Cell lines are useful models to study cell behavior and to develop tissue engineering strategies, because permanent cells are available in abundance and are uniform in their phenotype. Sources for primary cells, especially human cells, are rare and interindividual differences between donors aggravate comparability and reproducibility of results during experimental series. Nevertheless, for clinical applications it is mandatory to use primary cells instead of cell lines. Therefore, the choice of cell lines used for developing a cell therapeutic approach is critical, and the chosen model should resemble its primary counterpart as close as possible. In the field of experimental RPE tissue engineering, most research groups use ARPE19 cells, which display great morphological similarity to primary RPE cells. However, so far data are missing if the response of ARPE-19 cells and primary cells to collagen type I is similar and if techniques developed for ARPE-19 cell sheet transplantation can be transferred to primary cells.

Here we investigate if and how three different human RPE cell populations, including primary RPE cells, Simian virus 40 (SV40)-transfected RPE cells and ARPE-19 cells, respond specifically to two-dimensional collagen type I matrices that consist of a single layer of laterally joined, parallel collagen fibrils. We further examine if the nanostructure of these matrices provides a mechanical stimulus for directed migration. We also analyze the morphodynamic behavior of these RPE cell populations on the matrices using time-lapse microscopy and correlated these findings to protein expression of the collagen type I-specific integrin subunit $\alpha_{2}$. 


\section{Materials and Methods}

\section{Cell Culture}

Three different adult human RPE cell populations were used. In detail, primary adult human RPE cells were isolated from freshly dissected donor eyes and cultured in medium F99 (Medium 199/Ham's F12; Biochrom AG) supplemented with 5\% fetal calf serum (Gibco Invitrogen), $1 \mathrm{~mm}$ sodium pyruvate (Biochrom AG), $1 \mu$ g human recombinant insulin/ml (Gibco Invitrogen) and antibiotics $(50 \mu \mathrm{g} / \mathrm{ml}$ gentamicin and $250 \mu \mathrm{g} / \mathrm{ml}$ amphotericin B; Biochrom AG) as described previously [Valtink et al., 1999]. Primary cells, termed 'primary' in order to distinguish them from genetically manipulated cells (SV40-RPE) or naturally transformed cells (ARPE-19), were used up to passage P6. Adult human RPE cells which were transfected with large $\mathrm{T}$ - and small t-antigen of the SV40 expressed under a temperature-sensitive promoter with a permissive temperature of $33^{\circ} \mathrm{C}$ to introduce conditional proliferative activity (termed SV40-RPE cells) were cultured in the same medium. Cells were grown in gelatin-coated cell culture flasks and passaged at preconfluence by trypsinization. ARPE-19 cells (ATCC No. CRL-2302) were cultured in Dulbecco's modified Eagle's medium (high glucose, w/glutamin)/Ham's F12 (Ham's F12 Nutrient Mixture; Biochrom AG) supplemented with $10 \%$ fetal bovine serum and antibiotics as recommended by the supplier. For integrin blocking experiments cells were pretreated with a monoclonal anti-integrin subunit $\alpha_{2}$ antibody (clone P1H5; Santa Cruz Biotechnology Inc.) at a concentration of $10 \mu \mathrm{g} / \mathrm{ml}$ for 30 min before seeding onto nanostructured collagen matrices. Control experiments were performed likewise, but with an unspecific mouse IgG (mouse IgG2b; DakoCytomation) instead of the antiintegrin subunit $\alpha_{2}$ antibody.

\section{Preparation of Collagen Matrices}

Mica discs (diameter $1 \mathrm{~cm}$ ) were attached to the middle of tissue culture dishes (diameter $3 \mathrm{~cm}$ ) using an optical adhesive (Dymax Europe $\mathrm{GmbH}$ ). Solubilized bovine dermal collagen type I ( $3 \mathrm{mg} / \mathrm{ml}$; Cohesion) was diluted to a final concentration of 0.1 $\mathrm{mg} / \mathrm{ml}$ in $200 \mathrm{mM} \mathrm{KCl} / 50 \mathrm{~mm}$ glycine $\mathrm{pH}$ 9.2, applied onto a freshly cleaved mica surface and incubated at room temperature overnight. Unbound collagen was removed by several PBS washes. This protocol yielded two-dimensional matrices of parallel aligned fibrils with a thickness of approximately $3 \mathrm{~nm}$, showing characteristic D-periodicity.

\section{Photochemical Cross-Linking}

The collagen matrices were cross-linked using UV-A irradiation and riboflavin as a photosensitizer to increase mechanical stability [Spoerl et al., 1998]. Briefly, riboflavin solution (0.5\%; Jenapharm) was pipetted onto the collagen matrices. Subsequently matrices were irradiated with UV-A at $370 \mathrm{~nm}$ using a UV-A double diode (Roithner Lasertechnik) for $5 \mathrm{~min}$ to $4 \mathrm{~h}$. The light beam spot covered the entire collagen sample with $3 \mathrm{~mW} / \mathrm{cm}^{2}$. Surface irradiance was controlled with a calibrated UV-A meter (LaserMate-Q, LASER 2000). Maximum stability was reached after $45 \mathrm{~min}$ of UV-A irradiation and could not be increased further by longer irradiation times.

\section{Time-Lapse Phase Contrast Microscopy}

$1.5 \times 10^{5}$ cells were seeded onto freshly prepared collagen matrices. Phase contrast images were obtained using an Axiovert 200
$M$ inverted microscope (Zeiss) equipped with a CoolSnap HQ CCD camera (Photometrics) driven by Metamorph imaging software (Universal Imaging). Time-lapse images of cell alignment were collected every 3 min over $20 \mathrm{~h}$. During the observation period, cells were kept at $37^{\circ} \mathrm{C}$. Time-lapse experiments were performed with at least 3 different cultures per subpopulation on native and cross-linked collagen type I matrices. At least 3 different early passage cultures (P0-P3) and 3 different late passage cultures (P5-P6) of primary RPE and SV40-RPE were analyzed on native and cross-linked matrices.

\section{Cell Orientation and Shape Index}

Representative images of each cell population were acquired 150 min after seeding onto collagen matrices. An ellipse was fitted to the outline of each cell in the frame to obtain its major axis orientation in degrees relative to the positive $\mathrm{x}$-axis in the image frame, as well as the ratio of the minor and major axis length of the fitted ellipse. The major cell axis was measured for 10 highly aligned cells in each frame. The average of these 10 values was used as the direction of collagen fibril orientation in the frame, according to previously published results on fibroblasts [Poole et al., 2005]. To quantitatively determine the level of cell alignment along the collagen fibrils, the deviation of the major cell axis from collagen fibril orientation was calculated. The quadrant was chosen so that the maximum angle difference was $90^{\circ}$. To evaluate cell elongation, the ratio of minor and major axis length of the fitted ellipse was displayed as a shape index with values approaching 0 for highly elongated cells and 1 for rounded cells. A two-tailed Mann-Whitney test was used for statistical analysis.

\section{Immunohistochemistry}

Cells were seeded on uncoated glass coverslips and cultured until 5 days after confluence (overall cultivation time 2-3 weeks). Primary RPE cells were used up to passage P3. After fixation in ice-cold methanol for $20 \mathrm{~min}$, cells were permeabilized with $0.2 \%$ Triton-X 100/PBS and washed in $0.5 \%$ BSA/PBS for $20 \mathrm{~min}$. Cells were then incubated with monoclonal primary antibodies against collagen type I (clone I-8H5, 1:100; Acris), type IV (clone NLI/53, 1:40; Acris) or MMP-2 (clone CA-4001, 1:100; Merck Biosciences $\mathrm{GmbH}$ ) for $1 \mathrm{~h}$ at room temperature. Bound antibody was detected using FITC-conjugated secondary anti-mouse antibody (Sigma, 1:1,000) for $1 \mathrm{~h}$ at room temperature. Cell nuclei were stained using DAPI (Sigma, 1:5,000). Images were acquired using a LSM 510 META laser scanning confocal microscope $(60 \times$ PlanApo oil objective, NA 1.1; Zeiss). Immunostaining was performed twice on different cultures with duplicates in each experimental setup. Negative control reactions were performed without primary antibody.

\section{Western Blot}

Cells were cultured on cell culture dishes as described above. Cells were grown to confluence and lysed in 1\% Triton-X 100, 150 $\mathrm{mm} \mathrm{NaCl}, 10 \mathrm{~mm}$ Tris/HCl pH 7.5, 1 mM EDTA, $25 \mathrm{~mm} \mathrm{NaF}$ and protease inhibitor (Complete Mini; Roche Applied Science) on ice. Lysates were centrifuged for $20 \mathrm{~min}(16,000 \mathrm{~g})$ and the soluble fractions were either used immediately or stored at $-20^{\circ} \mathrm{C}$. Protein concentrations of the samples were determined by the Bradford protein assay (Biorad). Proteins were separated by SDS-PAGE and blotted onto nitrocellulose membranes using a semi-dry transfer system at $100 \mathrm{~V}$ for $1 \mathrm{~h}$. Membranes were blocked in 5\% nonfat 

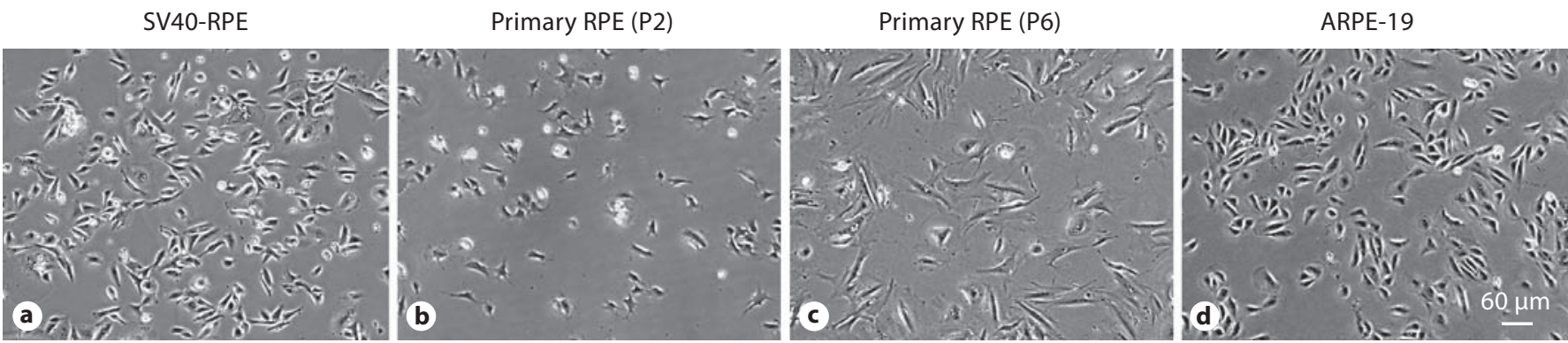

Fig. 1. Morphology of SV40-RPE (a) and primary RPE (b, c) cells cultured on amorphous collagen (gelatincoated culture flasks) and ARPE-19 cells (d) cultured on tissue culture-treated plastic. No preferential orientation was detected in any of the cultures. In later culture stages, flat spreading and stronger elongation could be seen for SV40-RPE (data not shown) and primary RPE (c). Phase contrast images were taken 2 days after seeding equal numbers of cells.

dry milk/PBS-T for $1 \mathrm{~h}$ at room temperature and subsequently incubated with a primary monoclonal mouse antibody to the integrin $\alpha_{2}$-subunit (clone 2; BD Transduction Laboratories) at a dilution of 1:500 for $1 \mathrm{~h}$ at room temperature. Bound antibody was detected with a HRP-conjugated secondary polyclonal sheep anti-mouse antibody (1:3,300, $1 \mathrm{~h}$ at room temperature; BD Transduction Laboratories) and ECL (Pierce). GAPDH staining (monoclonal mouse, clone 6C5, dilution 1:20,000, incubation overnight at $4^{\circ} \mathrm{C}$ ) served as loading control. Blots were digitally documented using an LAS-3000 imaging system (Fujifilm Corp.). Densitometric analysis of the bands was performed by determining pixel density using Image Gauge (Fujifilm Corp.) and Microsoft ${ }^{\circledR}$ Excel software. GAPDH bands were normalized and the intensities of the integrin subunit $\alpha_{2}$ bands were calculated respective to the normalized GAPDH band intensities. Western blotting was repeated 5 times with different lysates.

\section{Scanning Electron Microscopy}

SV40-RPE cells were grown on the nanostructured collagen type I matrix for $3 \mathrm{~h}$. Cells were fixed in $2.5 \%$ glutaraldehyde overnight and subsequently washed in $0.2 \mathrm{M}$ cacodylate buffer. Samples were dehydrated in ascending ethanol concentrations (30 to $100 \%$ in 6 steps), critically point-dried and sputtered with gold particles. Samples were analyzed in a Jeol JSM 7500F cold field emission scanning electron microscope.

\section{Results}

Cell Attachment on Amorphous, Denatured Collagen

We first examined SV40-RPE and primary RPE cells as species of retinal pigment epithelium on gelatin, which mainly consists of amorphous and denatured collagen type I. SV40-RPE and primary RPE cells attached quickly on this substratum and showed a partially elongated morphology (fig. 1). Primary cells in particular exhibited randomly organized cytoplasmic protrusions. In later culture stages, flat spreading and stronger elongation of

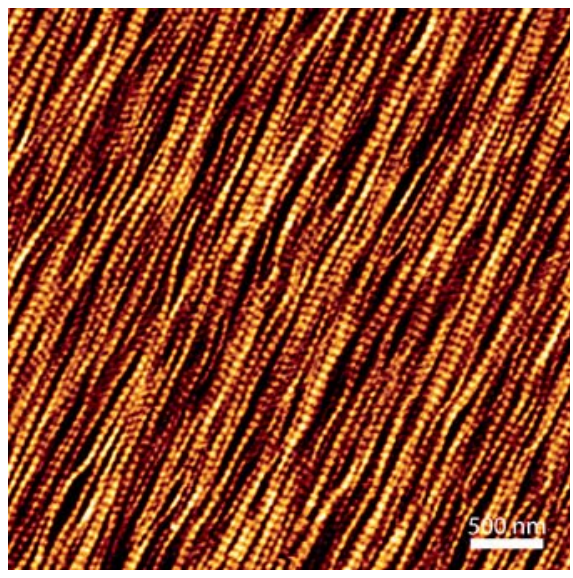

Fig. 2. Ultrastructure of the self-assembled collagen type I matrix as examined by atomic force microscopy using piezoelectric scanners with a scan range of $100 \times 100 \mu \mathrm{m}^{2}$ and oxide-sharpened $\mathrm{Si}_{3} \mathrm{~N}_{4}$ cantilevers with a nominal force constant of $0.09 \mathrm{~N} / \mathrm{m}$. Imaging was performed in contact mode. The matrix consists of a single layer of parallel fibrils showing the characteristic D-band periodicity.

SV40-RPE (data not shown) and primary RPE could be observed (fig. 1c). No preferential cell orientation was detected. ARPE-19 cells were grown on tissue culture plastic as recommended by the supplier, and formed regular arrays of polygonal cells. Again, no preferential orientation of the cells could be observed (fig. 1d).

\section{Cell Attachment and Migration on Nanostructured Collagen Type I Matrices}

Morphology and migration of SV40-RPE cells seeded on nanoscopically defined collagen matrices (fig. 2) were 


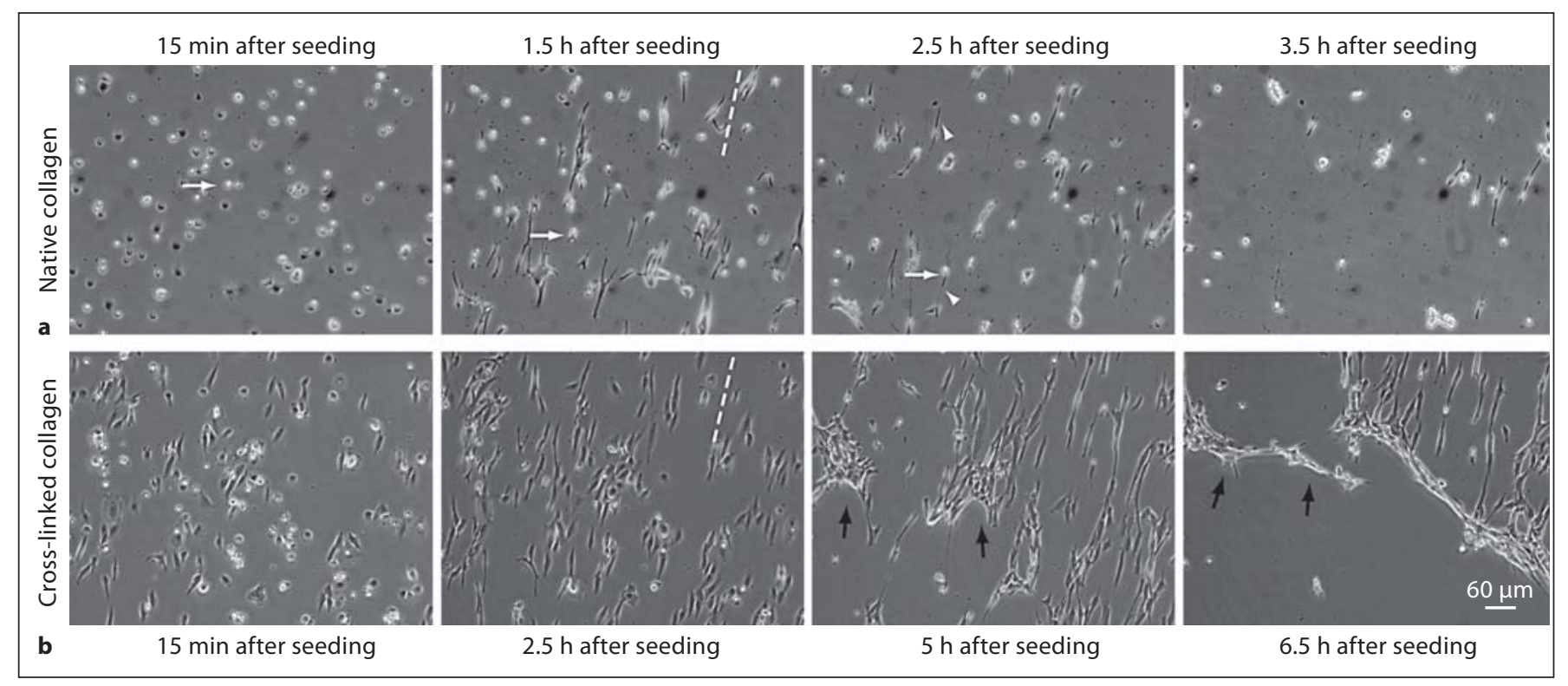

Fig. 3. Time-lapse video microscopy of SV40-RPE cells on nanopatterned collagen type I. Dashed lines reflect the collagen orientation. a SV40-RPE cells were seeded on nanostructured two-dimensional matrices of highly aligned collagen type I. Cells attached and aligned quickly to the collagen orientation. Cell migration occurred in the direction of the collagen orientation (white arrows tracking a cell). Matrix disruption was detected by the appearance of fine, dark lines $(2.5 \mathrm{~h})$ (white arrowheads). Cells disrupted the collagen array during alignment and rounded. b SV40-RPE seeded on UV-A/riboflavin cross-linked collagen matrices attached, aligned and started to migrate along the collagen fibrils. Sheet-like detachment occurred after $5 \mathrm{~h}$. Matrix destruction is indicated by black arrows ( 5 and $6.5 \mathrm{~h}$ ). examined over different time periods using time-lapse phase contrast microscopy (fig. 3). Cells attached to the native collagen matrix and elongated within 15 min after seeding. They formed bidirectional cellular protrusions parallel to the collagen axis (fig. 3a; $1.5 \mathrm{~h}$ ). Tracking single cells on the collagen matrix showed migration parallel to the direction of the collagen fibrils (fig. 3a). With increasing resting time, individual SV40-RPE cells started to destroy the underlying matrix by pulling fibrils apart. Such matrix disruption was indicated by the appearance of fine, dark lines that were clearly distinguishable from cellular protrusions and extended in the direction of the long cellular axis (fig. 3a; $2.5 \mathrm{~h}$ ). Additional SEM analysis confirmed matrix disruption by the cells (fig. 4). As an apparent consequence of these subtle defects in the collagen matrix, local differences in matrix density formed and the cells rounded up (fig. 3a; $3.5 \mathrm{~h}$; online suppl. video M1, www.karger.com/doi/10.1159/000323653). To prevent rapid matrix disruption, its mechanical strength was increased using simultaneous UV-A/riboflavin treatment known to induce singlet oxygen production which in turn leads to covalent bond formation between collagen fibril side chains [Spoerl et al., 1998]. Similar to the behavior on native matrices, SV40-RPE cells quickly spread and subsequently aligned parallel to the orientation of the collagen fibrils on these cross-linked matrices (fig. 3b; $15 \mathrm{~min}$ ). Cell-induced destruction of matrix integrity was delayed. After approximately $5 \mathrm{~h}$, the cells began to detach as a sheet together with the underlying matrix, indicating its enhanced biomechanical stability (fig. 3b; online suppl. video M2).

Primary RPE cells quickly attached to the native collagen matrix (fig. $5 \mathrm{a} ; 15 \mathrm{~min}$ ), but compared to SV40-RPE cells, alignment was delayed (fig. $5 \mathrm{a} ; 2.5 \mathrm{~h}$ ). It took up to $20 \mathrm{~h}$ until the majority of cells aligned parallel to the collagen orientation (fig. 5a; 20 h). Even after prolonged incubation times exceeding $20 \mathrm{~h}$, no matrix disruption was observed (online suppl. video M3). On UV-A/riboflavin cross-linked matrices, cells spread within 15 min and aligned parallel to the collagen orientation within $2.5 \mathrm{~h}$ (fig. 5b). Interestingly, despite seeding a similar number of cells, coverage was markedly increased on cross-linked collagen matrices as shown by the formation of an almost completely confluent monolayer of aligned cells by $20 \mathrm{~h}$ (fig. 5b and online suppl. video M4). This was presumably caused by extensive cell spreading. Notably, we found a 

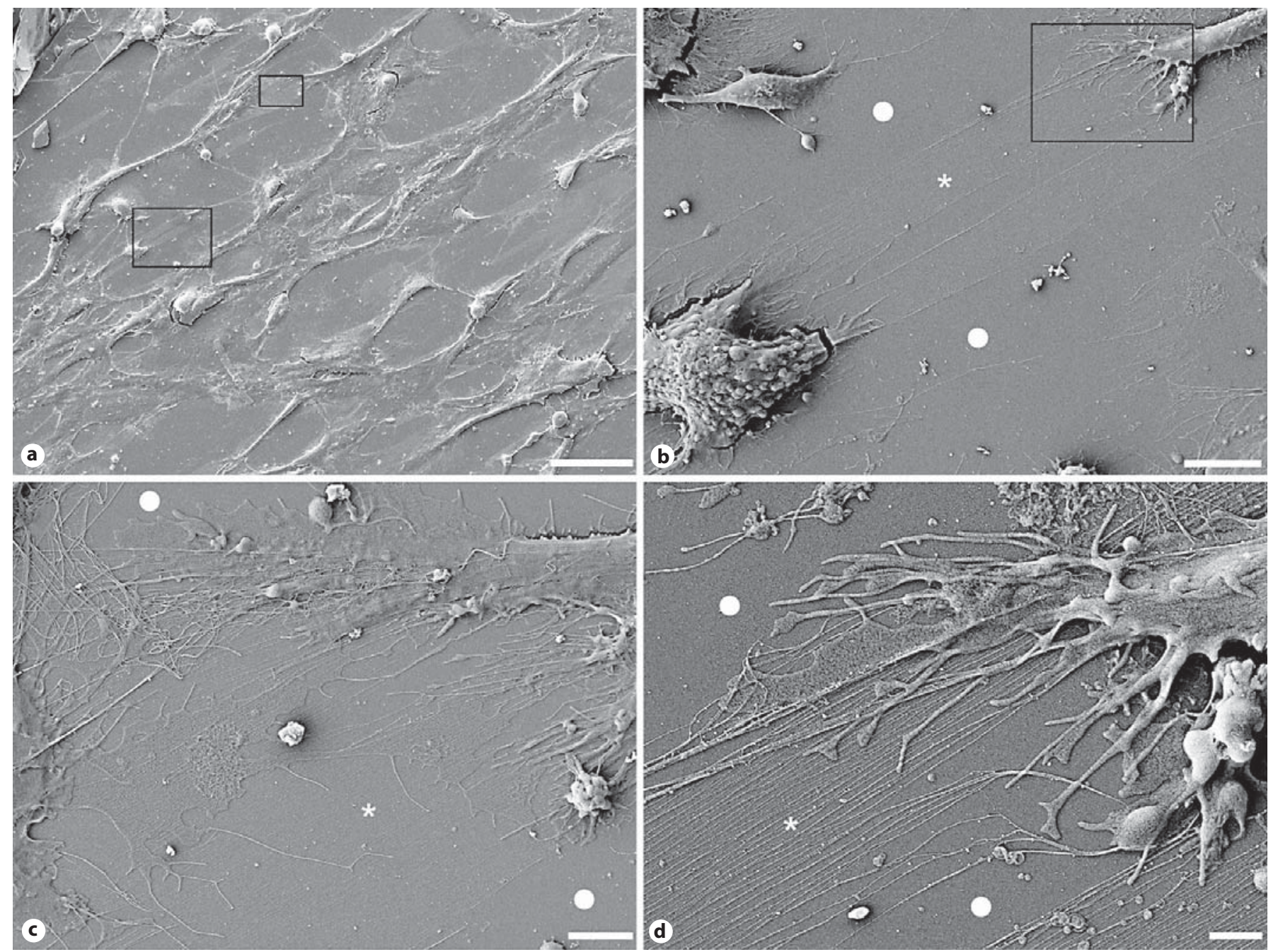

Fig. 4. Scanning electron microscopic analysis of SV40-RPE cells on native nanostructured collagen type I matrix reveals areas where the collagen type I fibrils are still aligned $\left(^{*}\right)$ or where the collagen has been removed by the cells (O). a Aligned SV40-RPE cells on nanostructured collagen type I. Scale bar $=100 \mu \mathrm{m}$. b Magnification of the big inset in a. Scale bar $=10 \mu \mathrm{m}$. Parallel, aligned collagen type I fibrils $\left({ }^{*}\right)$ as well as collagen-free areas are

visible between cells. c Magnification of the small inset in a. Scale bar $=5 \mu \mathrm{m}$. Bundled and ripped collagen type I fibrils can be seen between aligned fibrils $\left(^{*}\right)$ and collagen-free areas $(\circ)$. d Magnification of the inset in b. Scale bar $=3 \mu \mathrm{m}$. Bundled but still aligned collagen type I fibrils $\left(^{*}\right)$ as well as collagen-free areas (○) are displayed.

passage-dependent change in primary RPE cell behavior on cross-linked collagen matrices. While early passage (P0-3) primary RPE cells attached and aligned without signs of matrix destruction over $20 \mathrm{~h}$ (online suppl. video M4), later passage (P5-6) primary RPE cells attached very quickly and destroyed the integrity of the crosslinked matrix already after approximately $3 \mathrm{~h}$ (online suppl. video M5).

ARPE-19 cells attached to the native collagen matrices within 30 min (fig. 6a), but only a small number of cells

elongated parallel to the collagen fibrils even after extended incubation periods (fig. 6a; $20 \mathrm{~h}$ ). Within the observation period, ARPE-19 cells influenced the matrix only minimally. However, random cell movement with repeated cell extension and retraction cycles led to the formation of laterally joined collagen fibrils (online suppl. video M6). In contrast to native matrices, cell alignment was observed as early as $15 \mathrm{~min}$ post-seeding on cross-linked matrices (fig. 6b; 15 min). Cells remodeled the collagen fibrils in cross-linked matrices (online 


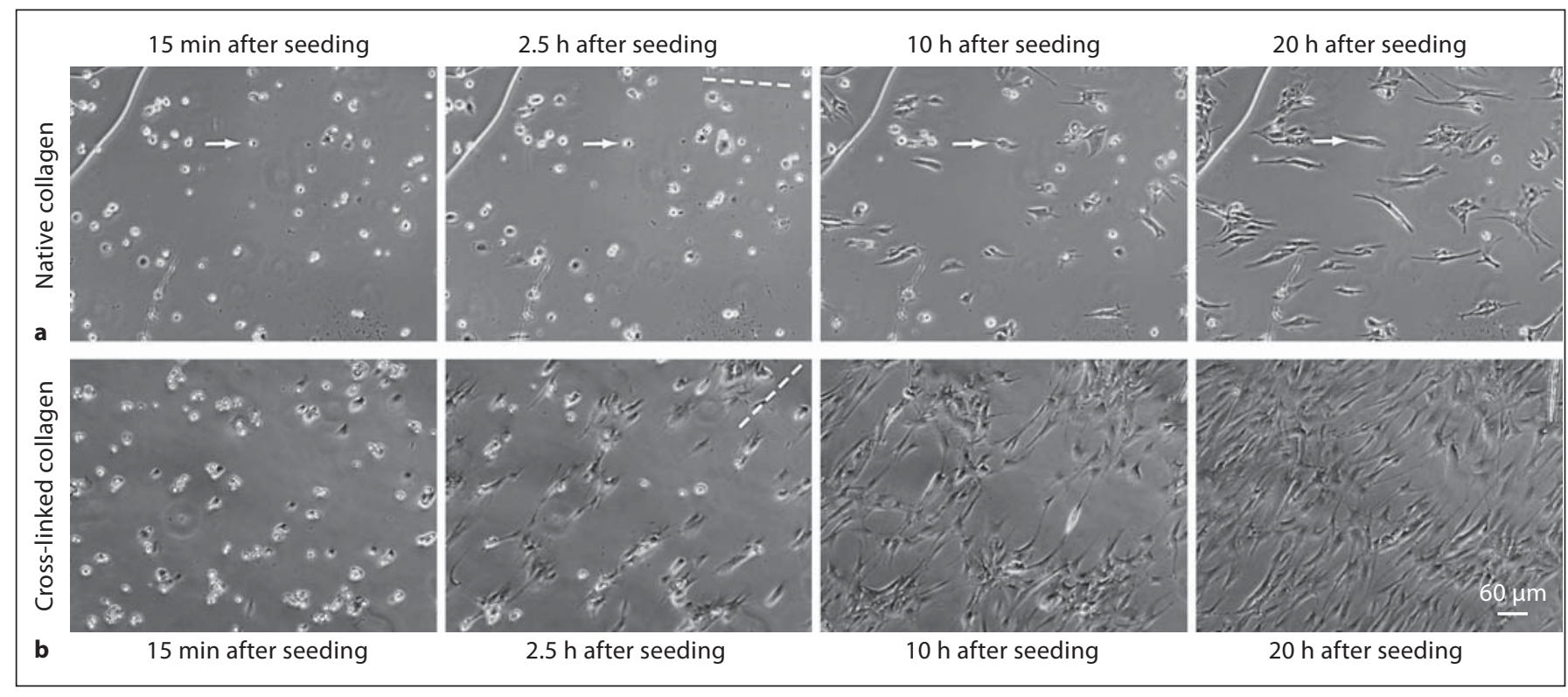

Fig. 5. Time-lapse video microscopy of primary RPE cells on nanopatterned collagen type I. Dashed lines reflect the collagen orientation. Primary RPE cells (P0-2) were seeded on native (a) and UV-A/riboflavin cross-linked (b) collagen matrices. Alignment was delayed on native matrices, whereas UV-A/riboflavin cross-linking improved alignment of cells and facilitated cell spreading. Cells migrated along the collagen fibrils (white arrows tracking a cell in a). Matrix destruction was not observed on native or UV-A/riboflavin cross-linked matrices, even during observation times exceeding $20 \mathrm{~h}$.

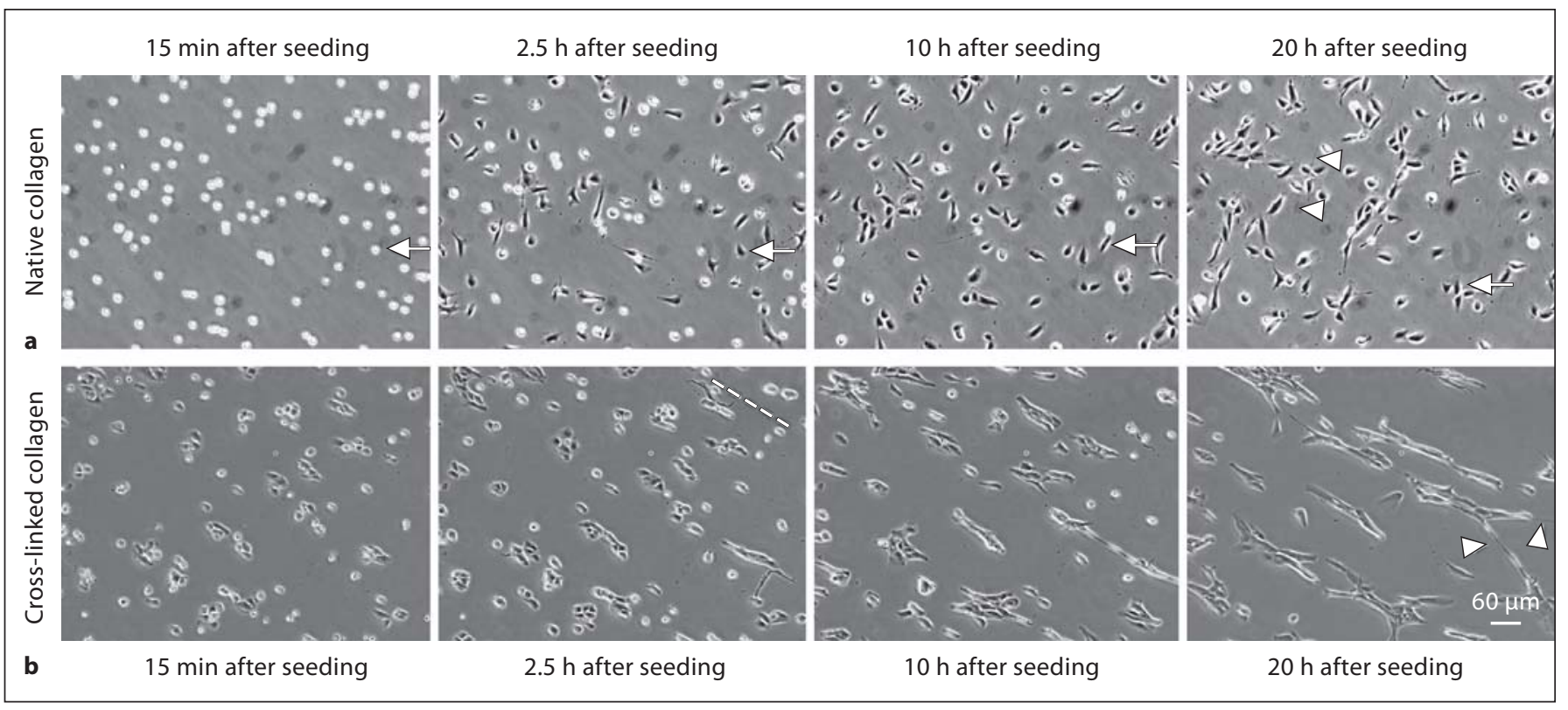

Fig. 6. Time-lapse video microscopy of ARPE-19 cells on nanopatterned collagen type I. Dashed lines reflect the collagen orientation. a Cell alignment of ARPE-19 cells on native collagen matrices was poor (white arrows tracking a cell). Random cell movement with repeated cell process extension and retrac- tion influenced the collagen matrix, leading to laterally joined collagen fibrils (white arrowheads). b UV-A/riboflavin crosslinking greatly facilitated ARPE-19 cell alignment (2.5 h). During alignment, the collagen fibrils were remodeled, indicated by visible, laterally joined collagen fibrils. 


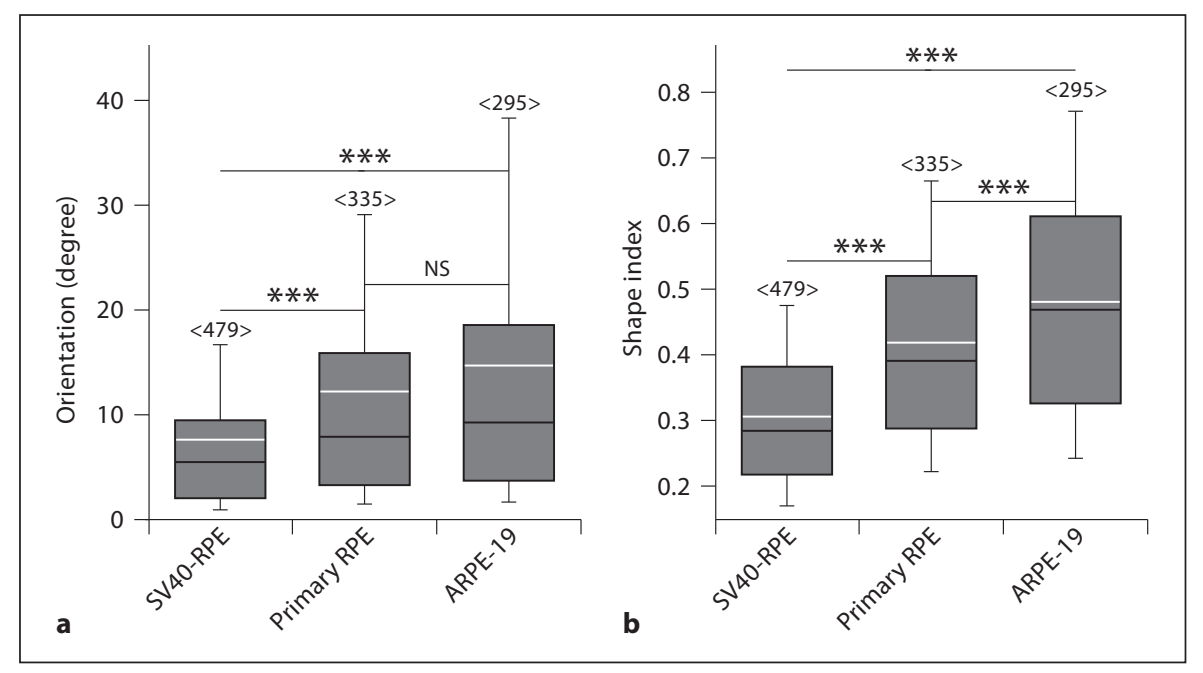

Fig. 7. Cell orientation (a) and shape index (b) of human SV40RPE, primary RPE and ARPE-19 cells on UV-A/riboflavin crosslinked matrices. Fifty percent of the data is located within the box, $80 \%$ within the whiskers. The black line represents the median and the white line indicates the mean of all data. Numbers of examined cells are given in angled brackets. a Cell orientation was determined as the difference between the orientation of the major axis of an ellipse fitted to the cell body and collagen orientation. A high percentage of SV40-RPE cells had an almost parallel alignment to the collagen axis. In contrast, only $50 \%$ of primary RPE and ARPE- 19 cells oriented with a maximal $20^{\circ}$ deviation to the collagen axis. A two-tailed Mann-Whitney test confirmed that
SV40-RPE cells had a significantly better alignment than primary RPE and ARPE-19 cells with $\mathrm{p}<0.001$. The difference in alignment between primary RPE and ARPE-19 was not significant $(p>0.05)$. $\mathbf{b}$ The shape index, calculated as the ratio of the minor and major axes of an ellipse fitted to each cell contour, yields values between 0 and 1 , with values approaching 0 representing a thin and strongly elongated cell and values approaching 1 representing a round cell. SV40-RPE cells had the most stretched appearance, while primary RPE and ARPE-19 cells retained a rounder shape. Statistical tests confirmed significant differences between all three RPE populations $(p<0.001)$ for the shape index.

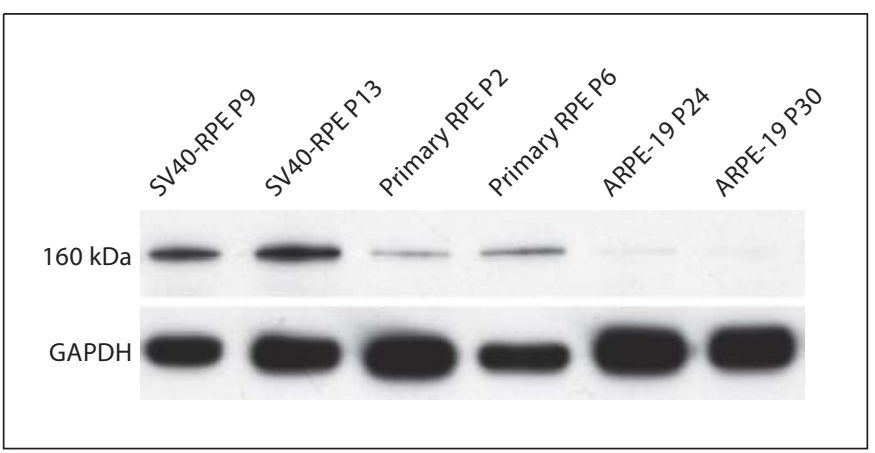

Fig. 8. Western blot analysis of integrin subunit $\alpha_{2}$ production in human SV40-RPE, primary RPE and ARPE-19 cells. Protein concentrations of total cell lysates were determined and normalized before analysis. GAPDH staining served as a control to confirm loading of equal amounts of protein. Densitometric analysis and normalization of integrin subunit $\alpha_{2}$ bands to GAPDH bands revealed a markedly higher integrin subunit $\alpha_{2}$ production in SV40RPE than in primary RPE or ARPE-19 cells. Furthermore, integrin subunit $\alpha_{2}$ production was distinctly increased in primary cells of higher passages. suppl. video M7), again leading to the formation of laterally joined collagen fibrils. Overall, ARPE-19 cell alignment was less pronounced compared to SV40-RPE or primary RPE cells irrespective of seeding on native or crosslinked matrices.

\section{Statistical Analysis of Cell Body Alignment and Shape Index}

Since the time needed for cell alignment varied between RPE cell populations and SV40-RPE quickly destroyed native matrices, a statistical analysis of cell body alignment and cell morphology was only possible on cross-linked matrices. Cell body alignment was defined as the orientation of the major axis of an ellipse fitted for maximum overlap with the cell body in relation to the collagen fibril orientation. In agreement with the phase contrast images described in the previous section, SV40RPE showed the best alignment with $80 \%$ of cells ranging within a $20^{\circ}$ deviation, while only approximately $50 \%$ of primary RPE cells and $50 \%$ of ARPE- 19 cells ranged within a $20^{\circ}$ deviation (fig. $7 \mathrm{a}$ ). Both cell types showed a 


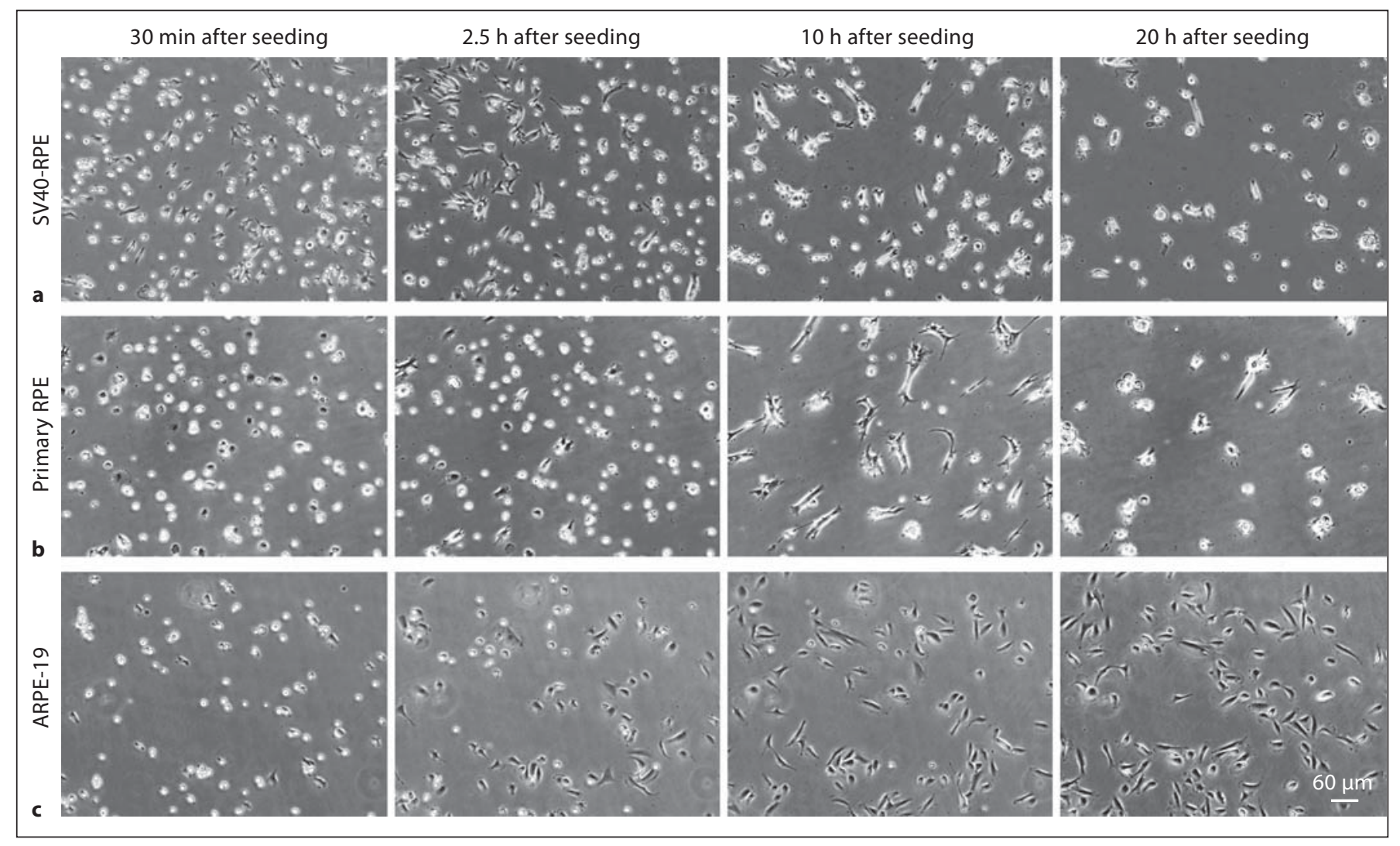

Fig. 9. Time-lapse video microscopy of SV40-RPE, primary RPE and ARPE-19 cells after pretreatment with a monoclonal antiintegrin subunit $\alpha_{2}$ antibody. a SV40-RPE showed impaired attachment and only a small number of cells aligned to the collagen matrix. b Primary RPE cells showed no cell alignment within the first $3 \mathrm{~h}$, but subsequently some cells started to align and simultaneously damaged the matrix. c ARPE-19 attached to the collagen matrix, but did not align or destroy the matrix. high degree of variability so that the difference in alignment between primary RPE and ARPE-19 cells was not statistically significant, although the differences in alignment can be considered meaningful from a cell biological point of view.

The shape index provides information about cell morphology in a two-dimensional plane and is calculated as the quotient of lengths of the minor and major axis of an ellipse fitted for maximum overlap with the cell body. Values approaching 0 represent highly elongated cells, while a value of 1 represents a circular cell. SV40-RPE had an overall stretched morphology (shape index $0.31 \pm$ 0.13; fig. 7b). In comparison, primary RPE and ARPE-19 cells were significantly less elongated, as indicated by a higher shape index (primary RPE shape index $0.42 \pm$ 0.17 ; ARPE-19 shape index $0.48 \pm 0.19$ ). Although similar cell body alignment values were obtained for ARPE-19 and primary cells, the shape index of ARPE-19 was sig- nificantly higher, revealing that ARPE-19 cells were less elongated.

\section{Analyzing Integrin Subunit $\alpha_{2}$ Protein Expression}

We investigated whether RPE cell alignment and matrix disruption correlated with the protein expression of the collagen-binding integrin $\alpha_{2} \beta_{1}$. Integrin subunit $\alpha_{2}$ levels were high in SV40-RPE cells (normalized pixel density: P9 $2.5 \times 10^{7}$ and P13 $\left.2.6 \times 10^{7}\right)$, moderate in primary RPE cells (normalized pixel density: P2 $3.6 \times 10^{6}$ and P6 $1.2 \times 10^{7}$ ) and very low in ARPE-19 cells (normalized pixel density: P24 $5.0 \times 10^{5}$ and P30 $4.5 \times 10^{5}$ ) (fig. 8). The protein levels positively correlated with the velocity and extent of cell alignment, as SV40-RPE cells spread and aligned more quickly than primary cells, and primary cells attached and spread faster and more pronounced than ARPE-19 cells. Considering that SV40-RPE cells destroyed the matrix very early during the alignment 


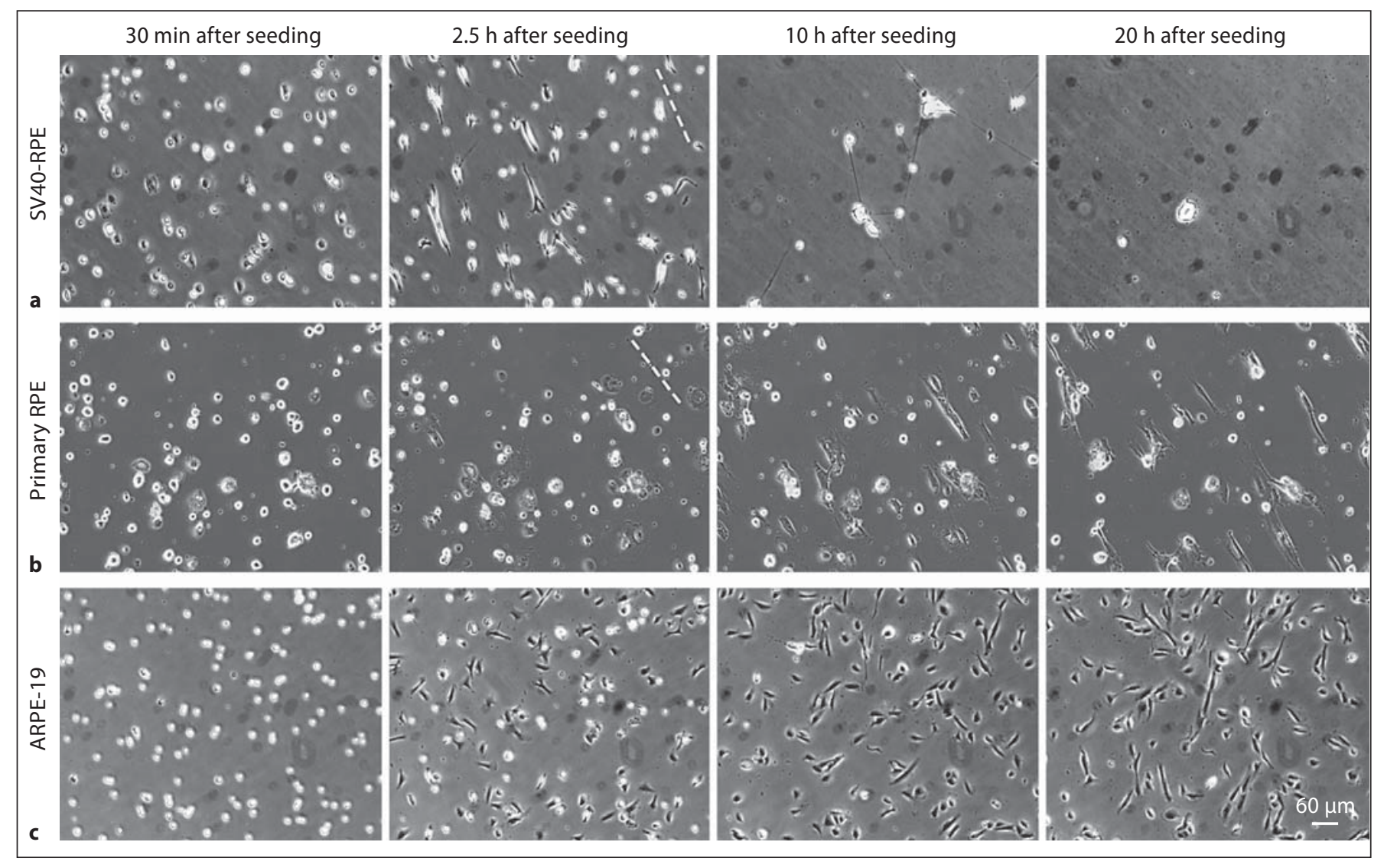

Fig. 10. Time-lapse video microscopy of SV40-RPE, primary RPE and ARPE-19 cells seeded on native nanostructured collagen type I matrices after pretreatment with a non-specific mouse IgG. Dashed lines reflect the collagen orientation. Attachment, alignment and migration of all three RPE populations on nanostructured collagen type I was comparable to that of untreated cells (fig. 3-6). a SV40-RPE were aligned within $2.5 \mathrm{~h}$ and disrupted the matrix within $3.5-10 \mathrm{~h}$. b Primary RPE cells started to align within $2.5 \mathrm{~h}$, but did not destroy the matrix during the entire observation period of $20 \mathrm{~h}$. c ARPE-19 showed attachment within $1 \mathrm{~h}$, but did not align to the collagen fibrils during the entire observation period of $20 \mathrm{~h}$. process, integrin subunit $\alpha_{2}$ protein expression seems to be partially associated with fast matrix destruction. Notably, a passage-dependent increase in integrin subunit $\alpha_{2}$ amounts up to 3 -fold was seen in primary RPE cells. This was reflected by a faster attachment and alignment of later passage cells (P6) compared to early passage cells (P2).

\section{Blocking of Integrin Subunit $\alpha_{2}$}

To demonstrate specific cell binding to native collagen type I matrices, integrin subunit $\alpha_{2}$ function was inhibited with a monoclonal blocking antibody. Nonspecific effects of the blocking antibody were excluded using an irrelevant IgG in isotype control experiments (fig. 10). Compared to untreated cells (fig. 3), pretreatment with the integrin subunit $\alpha_{2}$ function-blocking antibody reduced SV40-RPE cells attachment and spreading on the collagen matrix (fig. 9a). In addition, the majority of cells able to spread did not align along the collagen fibrils, but rather oriented randomly (fig. 9a; $2.5 \mathrm{~h}$ after seeding). Most of the cells that were pretreated with the blocking antibody remained rounded throughout the 20-hour observation period (fig. 9a). Due to this fact, the collagen matrix was not remodeled and remained largely intact. In contrast, SV40-RPE cells pretreated with the unspecific isotype control IgG were at first able to align along the collagen fibrils (fig. 10a; $2.5 \mathrm{~h}$ after seeding) and later severely disrupted the matrix. Thus, the irrelevant control antibody did not prevent cell-matrix interactions and matrix remodeling (fig. 10a; $20 \mathrm{~h}$ after seeding). The behavior of these cells closely resembled that of untreated SV40-RPE cells (fig. 3a). 


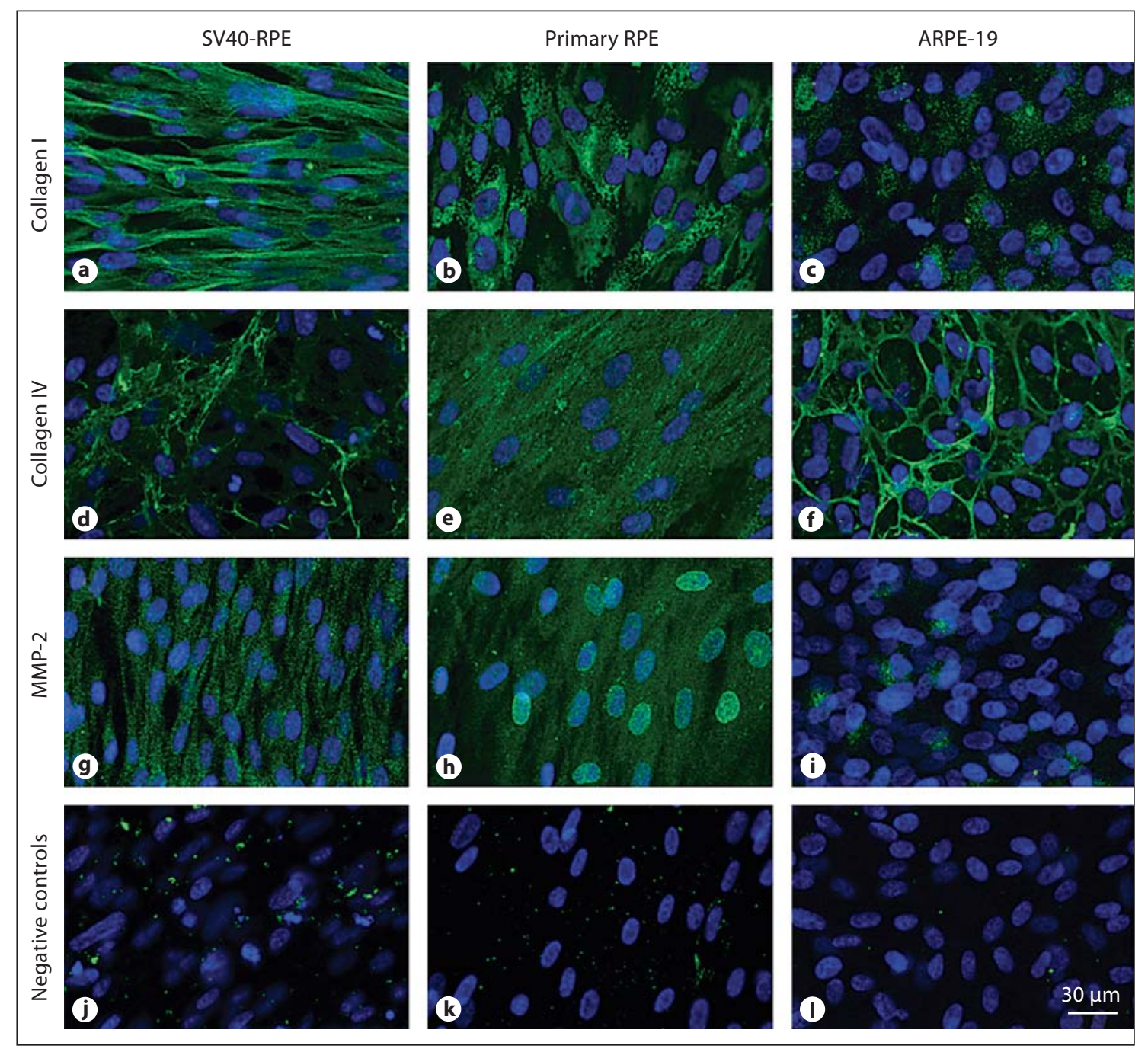

Fig. 11. Immunohistochemical images of human SV40-RPE, primary RPE and ARPE-19 cells. Staining was processed on uncoated glass coverslips for collagen type I, IV and MMP-2. SV40-RPE cells produced a higher amount of collagen type I than type IV, and produced detectable amounts of MMP-2. Primary RPE cells showed a cellular pattern of collagen type I and a fine, dense meshwork of collagen type IV. These cells were also positive for MMP-2. ARPE-19 cells showed almost no collagen type I and MMP-2 positivity, but had a reticular collagen type IV staining pattern.
In primary RPE cells, integrin subunit $\alpha_{2}$ blocking partially inhibited attachment, spreading and alignment to the collagen matrix (fig. 9b). After approximately $3 \mathrm{~h}$, a small fraction of the blocking antibody-treated cells started to align and partially disrupted the matrix. However, especially at the end of the observation period, elongation and alignment were reduced in blocked primary RPE cells compared to untreated primary RPE cells (fig. 5a) or cells pretreated with the unspecific isotype IgG (fig. 10b). Besides the observed culture age-dependent elevation of integrin subunit $\alpha_{2}$ expression in pri- mary RPE cells (fig. 8), reduction of adherence to and alignment along the fibrils by blocking also appeared to be influenced by variability between cultures derived from different donors (data not shown).

ARPE-19 cells pretreated with the blocking antibody adhered and spread for up to $20 \mathrm{~h}$, but did not align along the collagen fibrils and had little effect on matrix integrity (fig. 9c). ARPE-19 cells pretreated with an unspecific isotype IgG (fig. 10c) also adhered to the collagen matrix similar to untreated or blocked ARPE-19 cells (fig. 6a), and like these cells were unable to align along 
the matrix fibrils. These results indicate that ARPE-19 cell spreading and alignment along the native collagen fibrils occurs by an integrin subunit $\alpha_{2}$-independent mechanism.

\section{Collagen Production by Different Human RPE Populations}

All three human RPE cell populations were stained for collagen type I, type IV and MMP-2 to examine endogenous expression of these proteins, all of which may interfere with cellular orientation (fig. 11). Collagen type I was abundantly expressed in SV40-RPE cells and was deposited as filamentous structures corresponding to the cell shape. In ARPE-19 cells, only low levels of collagen type I with a granular, presumably intracellular, pattern were found. In primary RPE cells, localization of collagen type I corresponded to cell shape, but was probably not deposited as an extracellular meshwork since the staining did not appear filamentous (fig. 11a-c). High collagen type IV production was detected in primary RPE cells and ARPE-19 cells. Primary RPE cells produced a very densely packed collagen type IV network. ARPE-19 cells and SV40-RPE formed reticular collagen type IV meshworks (fig. 11d-f).

MMP-2 staining was strong in the cytoplasm of SV40$\mathrm{RPE}$ and primary RPE cells. In addition, primary RPE cells showed MMP-2-positive staining in the nuclei and in perinuclear regions. Only few ARPE-19 cells had detectable MMP-2 signals (fig. 11g-i). Negative controls performed without the primary antibodies confirmed specificity of the staining (fig. $11 j-1$ ).

\section{Discussion}

Cell-extracellular matrix (ECM) interactions play important roles in a variety of physiological and pathological processes. Increasing the understanding of cell-ECM interactions may aid the development of treatments for diseases such as AMD, in which ECM properties and conditions are critical for cell replacement strategies. We therefore examined cell behavior of human primary RPE cells and two RPE cell lines, SV40-RPE and ARPE-19, on artificial nanostructured collagen matrices. The aim of our study was to investigate whether RPE cells establish specific binding to these matrices and which cellular effects such specific binding may evoke. We found that although nanostructured collagen type I matrices are not suitable for long-term cultivation of RPE cells, they might serve as a potential tool to further investigate early steps of cell-matrix interactions. In contrast to amorphous collagen type I matrices, the defined pattern of the nanostructured matrix allowed us to directly visualize effects of matrix topography on RPE cell behavior, including alignment or migration. Characterization of these cellular functions is relevant to in vitro engineering and preservation of transplantable cell-matrix constructs. We were therefore also interested in analyzing differences in cellular behavior between various RPE cell populations on these matrices, which may have an impact on the choice of RPE cell species used as a model in experiments for developing RPE cell replacement strategies.

It is known that RPE cells adhere to amorphous collagen type I matrices [Abraham et al., 2007]. Our experiments demonstrate that all three RPE cell populations studied were able to bind specifically to nanopatterned matrices composed of parallel collagen type I fibrils. Out of the four known collagen-binding integrin receptors [White et al., 2004], integrin $\alpha_{2} \beta_{1}$ represents the main receptor mediating specific binding to fibrillar collagens [Heino, 2000]. In our study, alignment along the aligned collagen fibrils was decreased when endogenous integrin subunit $\alpha_{2}$ levels were low, as in ARPE-19 cells, or when integrin subunit $\alpha_{2}$ was blocked by preincubation with a blocking antibody. This indicates that integrin subunit $\alpha_{2}$ is primarily required for cell alignment along aligned collagen fibrils, as could be shown for human osteoblast-like cells that lack integrin $\alpha_{2} \beta_{1}$ [Friedrichs et al., 2007]. Considering that attachment of ARPE-19 cells was not influenced by integrin subunit $\alpha_{2}$ blocking, involvement of other collagen-binding integrins, such as integrin subunit $\alpha_{1}$, appears likely. In line with this argumentation, it was previously shown that integrin subunit $\alpha_{1}$ mediates binding to amorphous collagen in ARPE-19 cells [Bando et al., 2006; Morales et al., 2007]. Primary RPE cells of later passages resembled SV40-RPE cells more closely in that they aligned faster than early passage cells and detached in a sheet-like manner on cross-linked matrices. Together with the observed increase in integrin subunit $\alpha_{2}$ production, these results are in accordance with previous studies showing that integrin production levels in RPE cells increase with passage number [Gullapalli et al., 2008]. However, destruction of the collagen matrices could only partially be attributed to high integrin subunit $\alpha_{2}$ levels and strong binding to the collagen fibrils. For example, ARPE-19 cells, which express only very low levels of integrin subunit $\alpha_{2}$, destroyed the fragile collagen matrix by random cell movement with repeated cycles of cell process extension and retraction. Taken together, our results indicate that integrin $\alpha_{2} \beta_{1}$ mediates cell align- 
ment of all three RPE cell populations and to some extent also cell attachment of SV40-RPE to collagen type I.

As previously shown for fibroblasts using atomic force microscopy imaging [Friedrichs et al., 2007], mechanical cues within the nanostructured matrices contribute significantly to the mechanisms of cell alignment. The tensile strength of individual collagen fibrils is sufficient to withstand pulling forces exerted by cells, but the matrix is highly pliable perpendicular to the collagen fibrils. This anisotropy in matrix rigidity is the major cause of cell alignment [Friedrichs et al., 2007]. In order to stabilize the matrices and simultaneously preserve matrix anisotropy, we applied photochemical cross-linking with riboflavin under UV-A irradiation. Such photochemical cross-linking introduces covalent bonds between collagen side chains and is currently studied in experimental therapeutic approaches (www.clinicaltrials.gov, identifiers NCT00560651 and NCT00626717) to increase rigidity of the corneal stroma in patients with keratoconus [Wollensak, 2006]. In contrast to chemical cross-linking, for example by glutaraldehyde, this method stabilized the collagen matrices without impairing cell binding and aligning, as demonstrated by the accelerated alignment of all three cell populations. However, matrix disruption could not be prevented in all cases.

In addition to adhesion and detachment processes, ECM remodeling by building and cleaving molecules in the cellular environment also affects structure and stability of collagen matrices. Some interesting aspects emerged from immunohistochemical staining, where we found varying amounts of MMP-2, a gelatinase that digests collagen type I and IV, in all three RPE populations [Borrirukwanit et al., 2007; Gioia et al., 2007]. Given that binding to collagen type I stimulates MMP-2 secretion [Nguyen et al., 2000; Ruangpanit et al., 2001] and consid- ering that we observed the highest amount of collagen type I and notable MMP-2 production in SV40-RPE, enzymatically induced chemical changes in the matrix must therefore be considered. Hence, our findings support previous reports that integrin subunit $\alpha_{2}$-mediated outside-in signaling promotes collagen and collagenase synthesis [Heino, 2000].

In summary, our results suggest that the observed differences in attachment to, alignment on and disruption of the nanostructured collagen type I matrices by the three adult human RPE populations are due to cell-matrix interactions specific to each RPE cell population. We found that cellular spreading behavior depended mainly on the expression of the integrin subunit $\alpha_{2}$, the major receptor for collagen type I. The advantage of nanometerthin collagen matrices to provide a transferable growth and proliferation scaffold, for example for RPE cell sheet transplantation where introduction of thicker collagen membranes in the subretinal space is not desirable, is partially offset by their low mechanical stability. Our study further shows that cell adhesion and matrix remodeling are important features of RPE cells, but are expressed to varying degrees depending on the RPE cell species. Regarding attachment and alignment to collagen type I fibrils we found marked differences between ARPE-19 and primary RPE cells. These differences should be considered when using ARPE-19 or other nonprimary RPE cells as a model during the experimental phase of developing transplantable RPE sheets.

\section{Acknowledgements}

This work was supported by the Volkswagenstiftung. The authors wish to thank Doreen Streichert, Anja Neisser and Thomas Kurth for technical assistance.

\section{References}

Abraham, L.C., J.F. Dice, K. Lee, D.L. Kaplan (2007) Phagocytosis and remodeling of collagen matrices. Exp Cell Res 313: 1045-1055.

Bando, H., Y. Ikuno, Y. Hori, K. Sayanagi, Y. Tano (2006) Mitogen-activated protein kinase (MAPK) and phosphatidylinositol-3 kinase (PI3K) pathways differently regulate retinal pigment epithelial cell-mediated collagen gel contraction. Exp Eye Res 82: 529537.
Borrirukwanit, K., M.A. Lafleur, F.A. Mercuri, T. Blick, J.T. Price, R. Fridman, J.J. Pereira, V. Leardkamonkarn, E.W. Thompson (2007) The type I collagen induction of MT1-MMPmediated MMP-2 activation is repressed by $\alpha_{V} \beta_{3}$ integrin in human breast cancer cells. Matrix Biol 26: 291-305.

Castellarin, A.A., I.K. Sugino, J.A. Vargas, B. Parolini, G.M. Lui, M.A. Zarbin (1998) In vitro transplantation of fetal human retinal pigment epithelial cells onto human cadaver Bruch's membrane. Exp Eye Res 66: 4967.
Cisneros, D.A., J. Friedrichs, A. Taubenberger, C.M. Franz, D.J. Muller (2007) Creating ultrathin nanoscopic collagen matrices for biological and biotechnological applications. Small 3: 956-963.

Del Priore, L.V., L. Geng, T.H. Tezel, H.J. Kaplan (2002) Extracellular matrix ligands promote RPE attachment to inner Bruch's membrane. Curr Eye Res 25: 79-89.

Friedrichs, J., A. Taubenberger, C.M. Franz, D.J. Muller (2007) Cellular remodelling of individual collagen fibrils visualized by timelapse AFM. J Mol Biol 372: 594-607. 
Gioia, M., S. Monaco, G.F. Fasciglione, A. Coletti, A. Modesti, S. Marini, M. Coletta (2007) Characterization of the mechanisms by which gelatinase $\mathrm{A}$, neutrophil collagenase, and membrane-type metalloproteinase MMP-14 recognize collagen I and enzymatically process the two $\alpha$-chains. J Mol Biol 368: 1101-1113.

Gullapalli, V.K., I.K. Sugino, M.A. Zarbin (2008) Culture-induced increase in alpha integrin subunit expression in retinal pigment epithelium is important for improved resurfacing of aged human Bruch's membrane. Exp Eye Res 86: 189-200.

Heino, J. (2000) The collagen receptor integrins have distinct ligand recognition and signaling functions. Matrix Biol 19: 319-323.

Imai, H., S. Honda, N. Kondo, K. Ishibashi, Y. Tsukahara, A. Negi (2007) The upregulation of angiogenic gene expression in cultured retinal pigment epithelial cells grown on type I collagen. Curr Eye Res 32: 903-910.

Kubota, A., K. Nishida, M. Yamato, J. Yang, A. Kikuchi, T. Okano, Y. Tano (2006) Transplantable retinal pigment epithelial cell sheets for tissue engineering. Biomaterials 27: 3639-3644

Lu, J.T., C.J. Lee, S.F. Bent, H.A. Fishman, E.E. Sabelman (2007) Thin collagen film scaffolds for retinal epithelial cell culture. Biomaterials 28: 1486-1494.
Marshall, J., Hussain, A.A., Starita, C., Moore, D.J., Patmore, A.L. (1998) Aging and Bruch's membrane; in Marmor, M.F., Wolfensberger T.J. (eds) The Retinal Pigment Epithelium: Function and Disease. New York, Oxford University Press, pp 669-692.

Morales, S.A., S. Mareninov, P. Prasad, M. Wadehra, J. Braun, L.K. Gordon (2007) Collagen gel contraction by ARPE-19 cells is mediated by a FAK-Src dependent pathway. Exp Eye Res 85: 790-798.

Nguyen, M., J. Arkell, C.J. Jackson (2000) Threedimensional collagen matrices induce delayed but sustained activation of gelatinase $\mathrm{A}$ in human endothelial cells via MT1-MMP. Int J Biochem Cell Biol 32: 621-631.

Poole, K., K. Khairy, J. Friedrichs, C. Franz, D.A. Cisneros, J. Howard, D. Mueller (2005) Molecular-scale topographic cues induce the orientation and directional movement of fibroblasts on two-dimensional collagen surfaces. J Mol Biol 349: 380-386.

Ruangpanit, N., D. Chan, K. Holmbeck, H Birkedal-Hansen, J. Polarek, C. Yang, J.F. Bateman, E.W. Thompson (2001) Gelatinase A (MMP-2) activation by skin fibroblasts: dependence on MT1-MMP expression and fibrillar collagen form. Matrix Biol 20: $193-$ 203.

Spoerl, E., M. Huhle, T. Seiler (1998) Induction of cross-links in corneal tissue. Exp Eye Res 66: 97-103.

Thumann, G., A. Hueber, S. Dinslage, F. Schaefer, T. Yasukawa, B. Kirchhof, Y. Yafai, W. Eichler, A. Bringmann, P. Wiedemann (2006) Characteristics of iris and retinal pigment epithelial cells cultured on collagen type I membranes. Curr Eye Res 31: 241-249.
Thumann, G., A. Viethen, A. Gaebler, P. Walter, S. Kaempf, S. Johnen, A.K. Salz (2009) The in vitro and in vivo behaviour of retinal pigment epithelial cells cultured on ultrathin collagen membranes. Biomaterials 30: 287-294.

Tsukahara, I., S. Ninomiya, A. Castellarin, F. Yagi, I.K. Sugino, M.A. Zarbin (2002) Early attachment of uncultured retinal pigment epithelium from aged donors onto Bruch's membrane explants. Exp Eye Res 74: 255266

Valtink, M., K. Engelmann, O. Strauss, R. Kruger, C. Loliger, A.S. Ventura, G. Richard (1999) Physiological features of primary cultures and subcultures of human retinal pigment epithelial cells before and after cryopreservation for cell transplantation. Graefes Arch Clin Exp Ophthalmol 237: 1001-1006.

White, D.J., S. Puranen, M.S. Johnson, J. Heino (2004) The collagen receptor subfamily of the integrins. Int J Biochem Cell Biol 36: $1405-1410$.

Wollensak, G. (2006) Crosslinking treatment of progressive keratoconus: new hope. Curr Opin Ophthalmol 17: 356-360.

Zarbin, M.A. (2003) Analysis of retinal pigment epithelium integrin expression and adhesion to aged submacular human Bruch's membrane. Trans Am Ophthalmol Soc 101: 499520 . 